\title{
Communication
}

\section{D Finite Element Analysis of Rotary Instruments in Root Canal Dentine with Different Elastic Moduli}

\author{
Carlo Prati ${ }^{1, *}$, João Paulo Mendes Tribst ${ }^{2}{ }^{(0}$, Amanda Maria de Oliveira Dal Piva ${ }^{3}(\mathbb{C}$, \\ Alexandre Luiz Souto Borges ${ }^{3}\left[\right.$, , Maurizio Ventre ${ }^{4,5}$, Fausto Zamparini ${ }^{1}\left[\right.$ and Pietro Ausiello ${ }^{6}$
}

check for

updates

Citation: Prati, C.; Tribst, J.P.M.; Dal Piva, A.M.d.O.; Borges, A.L.S.; Ventre, M.; Zamparini, F.; Ausiello, P. 3D Finite Element Analysis of Rotary Instruments in Root Canal Dentine with Different Elastic Moduli. Appl. Sci. 2021, 11, 2547. https://doi.org/ 10.3390/app11062547

Academic Editor: Luca Testarelli

Received: 10 February 2021

Accepted: 8 March 2021

Published: 12 March 2021

Publisher's Note: MDPI stays neutral with regard to jurisdictional claims in published maps and institutional affiliations.

Copyright: (C) 2021 by the authors. Licensee MDPI, Basel, Switzerland. This article is an open access article distributed under the terms and conditions of the Creative Commons Attribution (CC BY) license (https:// creativecommons.org/licenses/by/ $4.0 /)$.
1 Endodontic Clinical Section, Department of Biomedical and Neuromotor Sciences, School of Dentistry, University of Bologna-Alma Mater Studiorum, 40125 Bologna, Italy; fausto.zamparini2@unibo.it

2 Postgraduate Program in Dentistry, University of Taubaté (UNITAU), Taubaté, São Paulo 12020-270, Brazil; joao.tribst@gmail.com

3 Department of Dental Materials and Prosthodontics, Institute of Science and Technology, São Paulo State University-UNESP, São Paulo 12245-000, Brazil; amodalpiva@gmail.com (A.M.d.O.D.P.); alexanborges@gmail.com (A.L.S.B.)

4 Department of Chemical, Materials and Industrial Production Engineering, University of Naples Federico II, 80125 Naples, Italy; maurizio.ventre@unina.it

5 Center for Advanced Biomaterials for HealthCare@CRIB, Istituto Italiano di Tecnologia, 80125 Naples, Italy

6 School of Dentistry, University of Naples Federico II, 80131 Naples, Italy; pietausi@unina.it

* Correspondence: carlo.prati@unibo.it

\begin{abstract}
The aim of the present investigation was to calculate the stress distribution generated in the root dentine canal during mechanical rotation of five different NiTi endodontic instruments by means of a finite element analysis (FEA). Two conventional alloy NiTi instruments F360 25/04 and F6 Skytaper 25/06, in comparison to three heat treated alloys NiTI Hyflex CM 25/04, Protaper Next 25/06 and One Curve 25/06 were considered and analyzed. The instruments' flexibility (reaction force) and geometrical features (cross section, conicity) were previously investigated. For each instrument, dentine root canals with two different elastic moduli(18 and $42 \mathrm{GPa}$ ) were simulated with defined apical ratios. Ten different CAD instrument models were created and their mechanical behaviors were analyzed by a 3D-FEA. Static structural analyses were performed with a non-failure condition, since a linear elastic behavior was assumed for all components. All the instruments generated a stress area concentration in correspondence to the root canal curvature at approx. $7 \mathrm{~mm}$ from the apex. The maximum values were found when instruments were analyzed in the highest elastic modulus dentine canal. Strain and von Mises stress patterns showed a higher concentration in the first part of curved radius of all the instruments. Conventional Ni-Ti endodontic instruments demonstrated higher stress magnitudes, regardless of the conicity of $4 \%$ and $6 \%$, and they showed the highest von Mises stress values in sound, as well as in mineralized dentine canals. Heat-treated endodontic instruments with higher flexibility values showed a reduced stress concentration map. Hyflex CM 25/04 displayed the lowest von Mises stress values of, respectively, 35.73 and $44.30 \mathrm{GPa}$ for sound and mineralized dentine. The mechanical behavior of all rotary endodontic instruments was influenced by the different elastic moduli and by the dentine canal rigidity.
\end{abstract}

Keywords: computer-aided design; finite element analysis; nickel-titanium alloys; endodontic treatment

\section{Introduction}

The superelasticity of nickel-titanium (Ni-Ti) shape memory alloys is considered the reason for the positive mechanical behavior (consisting of a nonlinear elastic behavior) that allows the material to undergo high deformation without plastic residual-strain after stress removal, during transforming from the austenite to martensitic phase [1]. The NiTi is only composed of two elements: titanium and nickel, however, the physical and mechanical 
properties of NiTi alloys are significantly different from pure titanium and nickel base alloys [2].

In dental practice, the phenomenon of NiTi endodontic instruments fracturing as a consequence of torsional overloading or cyclic fatigue is continually reported [3-5]. This usually happens when the tip of the instrument binds to the canal while the shaft continues to rotate [6]. On the other hand, flexural and fatigue failure occurs when the instrument rotates in the curved canal, before undergoing a great number of tensilecompressive strain cycles in the zone with maximum curvature. Instrument durability applies an important role during the management of endodontic compromised teeth to avoid mechanical complications during dental treatment [7].

In this sense, bending and torsion are considered critical conditions that must be investigated in order to understand the mechanical behavior of the endodontic instruments. Pitch length, taper and conicity, alloy chemical composition and thermomechanical processing are also main factors that influence the mechanical response of the alloy [8]. A close correlation has also been demonstrated between the cross-sectional shape and the stress distribution pattern of an endodontic instrument subjected to bending or torsion [9]. Taking into account the cross-sectional geometry, the bending orientation may have an important influence on the mechanical responses of the instrument.

Recently, thermomechanical treatment of NiTi alloys allowed for the design of a new generation of endodontic instruments characterized by a change in the phase composition, with the appearance of the martensite and/or $\mathrm{R}$ phase under clinical conditions $[9,10]$. This allowed for the introduction of new heat-treated NiTi endodontic instruments with different mechanical behaviors in comparison to the conventional ones [10,11]. Several laboratory tests were performed to study the flexibility and torsional stiffness of NiTi instruments during the conventional kinematics of rotary instrumentation [12].

Theoretical studies based on mathematical and numerical analyses have also been carried out in dentistry, by means of a finite element analysis (FEA), to calculate new mechanical and structural aspects of the behaviors of materials in endodontics, restorative or implant dentistry [13-19]. This tool can efficiently illustrate the stress distribution pattern through an analysis of finite small elements, the behavior of which can be summarized and calculated [20]. Moreover, FEA can easily provide the stress magnitude and distribution, as well as the influence of various materials which cannot be investigated by traditional in vitro tests [21].

The simulation of kinematics (rotation) occurs differently from traditional in vitro tests, such as in cyclic fatigue resistance tests [22-26], Weibull analyses [27], and metallurgical and micromorphological analyses $[22,23,28]$.

In all these studies, the friction of NiTi alloys is performed with devices simulating an artificial metallic canal (with a higher elastic modulus and hardness than in human dentine) with different curvature radii [22-26]. Currently, there is no standardized methodology to analyze the cyclic and torsional aspects involved in the fatigue test of NiTi instruments [29].

FEA has been successfully used in endodontics, revealing that it is an efficient tool to investigate, for example, the instrument mechanical responses in root canal simulations. Previous analyses successfully investigated the stress generated in the bending and torsion condition of the NiTi instrument in reason of their cross sections [30,31] or of their thermal treatment [1]. This kind of FEA was also used to predict the cyclic fatigue resistance of various NiTi instruments through the simulation of traditional testing devices [32,33]. It was also able to display the effect of root canal treatment procedures on the stress distribution in a tooth resin model [34]. However, there are no studies that have reported their mechanical behavior in simulated sound (normal) and high mineralized dentine elastic modulus root canal models.

For these reasons, there is a need to simulate NiTi instruments under more complete simulating clinical conditions and to analyze the stress distribution produced by different alloy endodontic instruments. In this context, the aim of the current research was to evaluate the mechanical behavior of five different commercially available NiTi instruments by 
means of a 3D-FEA, focusing the influence of the material-shape combination (conventional and heat-treated NiTi alloy, cross sectional design, conicity), as well as the elastic modulus of the dentine root canal (18 and $42 \mathrm{GPa}$ ).

The null hypothesis was that different endodontic instruments would not affect the von Mises stress and strain distributions in root dentine canals with different elastic moduli.

\section{Materials and Methods}

Five endodontic NiTi instruments, two composed of conventional alloys and three made of heat-treated alloys were considered $[10,11]$. Instruments were digitalized in a micro-CT scanner system (BrukermicroCT, Kontich, Belgium) and irradiated with an $\mathrm{x}$-ray beam at $90 \mathrm{kV}$ and the camera resolution was set at $9 \mu \mathrm{m} \cdot \mathrm{pixel}^{-1}$. Scans were acquired by revolving the specimen at a $1^{\circ}$ rotation step, thus, obtaining 360 projection images. The 3D model of the instruments was reconstructed by assembling (approximately) 700 cross sectional images. Briefly, image datasets were processed via ScanIP ${ }^{\circledR}(3.2$, Simpleware Ltd., Exeter, UK). Image segmentation and filtering procedures were used and a stereolithography model (STL) of the instruments was created.

The STL files were exported and a dedicated software (SpaceClaim 2019, ANSYS Company, Canonsburg, PA, USA) was employed (Figure 1). Then, the volume was checked, the gaps between triangular faces were fixed and small faces were merged into a single face. In sequence, 20 perpendicular planes were created along the endodontic instrument length (2 mm each) to split the STL file in segments. These segments were filled with a skin surface and joined to form one volumetric solid and exported in STEP (Standard for the Exchange of Product model data) format. These procedures were repeated for all the endodontic instruments.

F360\# $25,4 \%$

Hyflex CM \# 25, 4\%

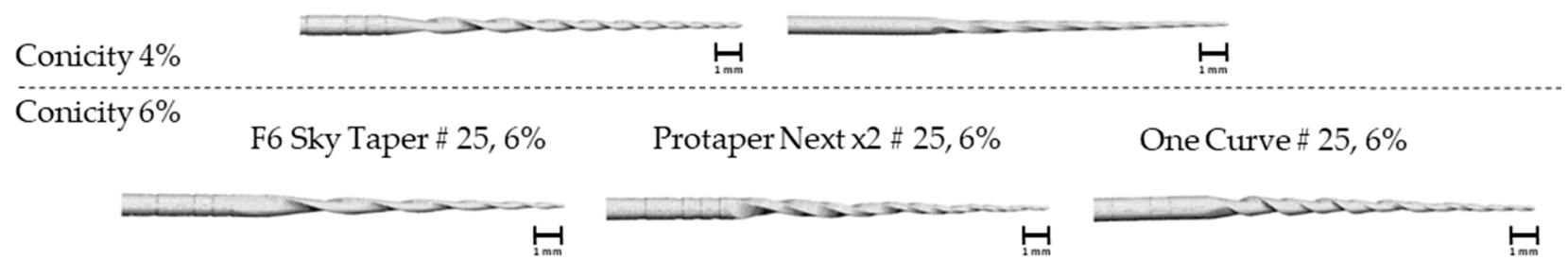

Figure 1. Stereolithography model (STL) files obtained with MicroCT of analyzed instruments. F360 and F6 Sky Taper are made of conventional NiTi alloy. Hyflex CM, Protaper Next and One Curve are constituted of heat treated NiTi alloys.

Using modeling software (Rhinoceros 6.0, McNeel North America, Seattle, WA, USA), an artificial canal was created. Thus, a three-dimensional rectangular solid $(32 \times 20 \times$ $6 \mathrm{~mm}$ ) was created containing a simulated canal with an angle of curvature of $90^{\circ}$, a radius of $5 \mathrm{~mm}$, with the center of the curvature $7 \mathrm{~mm}$ from the tip of the instrument. For each instrument, one specific canal was created presenting the same volume, conicity and shape than the instrument.

Five sets of canals and instruments were considered, and a computer assisted engineering software (ANSYS 17.2 Company, Commonwealth of Pennsylvania, USA) was used. A mesh convergence test (10\%) was carried out to assist with determining the number of nodes and elements for each set [35]. The technical features of the analyzed models are summarized in Table 1 . The frictional contact $(0.2)$ between the instrument and canal was assumed, according to the motion of the file into the root canal. The constraints were applied for nodal displacements at the bottom of the artificial curved canal in all directions. The volume of the instrument, reaction force in bending and elastic modulus of each instrument (according the employed NiTi alloy) are summarized in Table 2. 
Table 1. Technical features (manufacturer, conicity and NiTi alloy) of analyzed instruments and maximum torque recommended by manufacturers (N.cm).

\begin{tabular}{cccccc}
\hline Instrument \#25 & Manufacturer & $\begin{array}{c}\text { Conicity } \\
\mathbf{( \% )}\end{array}$ & Cross Section & $\begin{array}{c}\text { NiTi } \\
\text { Alloy }\end{array}$ & $\begin{array}{c}\text { Torque } \\
\mathbf{( N \cdot c m )}\end{array}$ \\
\hline Hyflex CM & $\begin{array}{c}\text { Coltene/Whaledent, } \\
\text { Altstätten, Switzerland }\end{array}$ & 4 & Quadrangular & Heat-treated & 2.5 [10] \\
\hline F360 & Komet, Lemgo, Germany & 4 & Quadrangular & Conventional & $1.8[10]$ \\
\hline One Curve & $\begin{array}{c}\text { Micro Mega, Besancon, } \\
\text { France }\end{array}$ & 6 & $\begin{array}{c}\text { S shaped at the shaft and } \\
\text { triangular at the tip }\end{array}$ & Heat-treated & 2.5 [11] \\
\hline F6 skytaper & Komet, Lemgo, Germany & 6 & S shaped & Conventional & 2.8 [10] \\
\hline Protaper Next X2 & $\begin{array}{c}\text { Dentsply Maillefer, } \\
\text { Baillagues, Switzerland }\end{array}$ & 6 & Rectangular & Heat-treated & $5.2[11]$ \\
\hline
\end{tabular}

Table 2. Volume of instruments, reaction force $(\mathrm{N})$ and stress peak of NiTi instruments according to the dentine elastic modulus (18 GPa and $42 \mathrm{GPa}$ ).

\begin{tabular}{ccccc}
\hline Instrument \#25 & $\begin{array}{c}\text { Volume } \\
\text { of Instrument } \\
\left(\mathbf{m m}^{\mathbf{3}} \mathbf{)}\right.\end{array}$ & $\begin{array}{c}\text { Reaction Force } \\
\text { in Bending } \\
\mathbf{( N )}\end{array}$ & 0.69 & \multicolumn{2}{c}{ Stress Peak (MPa) } \\
\cline { 3 - 5 } & 6.30 & 0.89 & $\begin{array}{c}\text { Sound Dentine } \\
\mathbf{( 1 8 ~ G P a )}\end{array}$ & $\begin{array}{c}\text { Mineralized Dentine } \\
\mathbf{( 4 2} \mathbf{~ G P a})\end{array}$ \\
\hline Hyflex CM & 6.07 & 1.91 & 35.73 & 220.05 \\
\hline F360 & 9.20 & 0.39 & 77.04 & 253.41 \\
\hline One Curve & 8.28 & 0.64 & 265.22 & 155.50 \\
\hline F6 Skytaper & 8.07 & 117.78 & 298.01 \\
\hline
\end{tabular}

Mechanical properties (elastic modulus-E, Poisson's ratio- $-v$ ) of two different dentine types were used: a sound dentine $(\mathrm{E}=18 \mathrm{GPa}, v=0.3)$ and a highly mineralized peritubular dentine $(\mathrm{E}=42 \mathrm{GPa}, v=0.3)[14,35,36]$. For a conventional NiTi alloy, a value of $43.9 \mathrm{GPa}$ was assumed for the elastic modulus, whereas $\mathrm{E}=24.6 \mathrm{GPa}$ was considered for the heat treated instruments [37].

Two different loading conditions were considered for each instrument at the same time (Figures 2 and 3). The first condition representing the bending moment during the insertion of the endodontic instrument inside of the curved canal is shown in Figure 2.

This reaction force during the instrument bending was dependent upon the shape (cross section), elastic modulus and displacement of the instrument. For this reason, this reaction force was assessed using a static structural analysis for each instrument, simulating the bending condition during insertion into the canal. The reaction force reported in $\mathrm{N}$ was recorded to be used in the second part of the simulation, with the instrument working in rotation inside the dentine root canal.

The second loading condition was the torque during the rotation. Thus, indications of the maximum torque according to each manufacturer were used (Table 1). Figure 3 represents both forces in the instrument at the same time. 

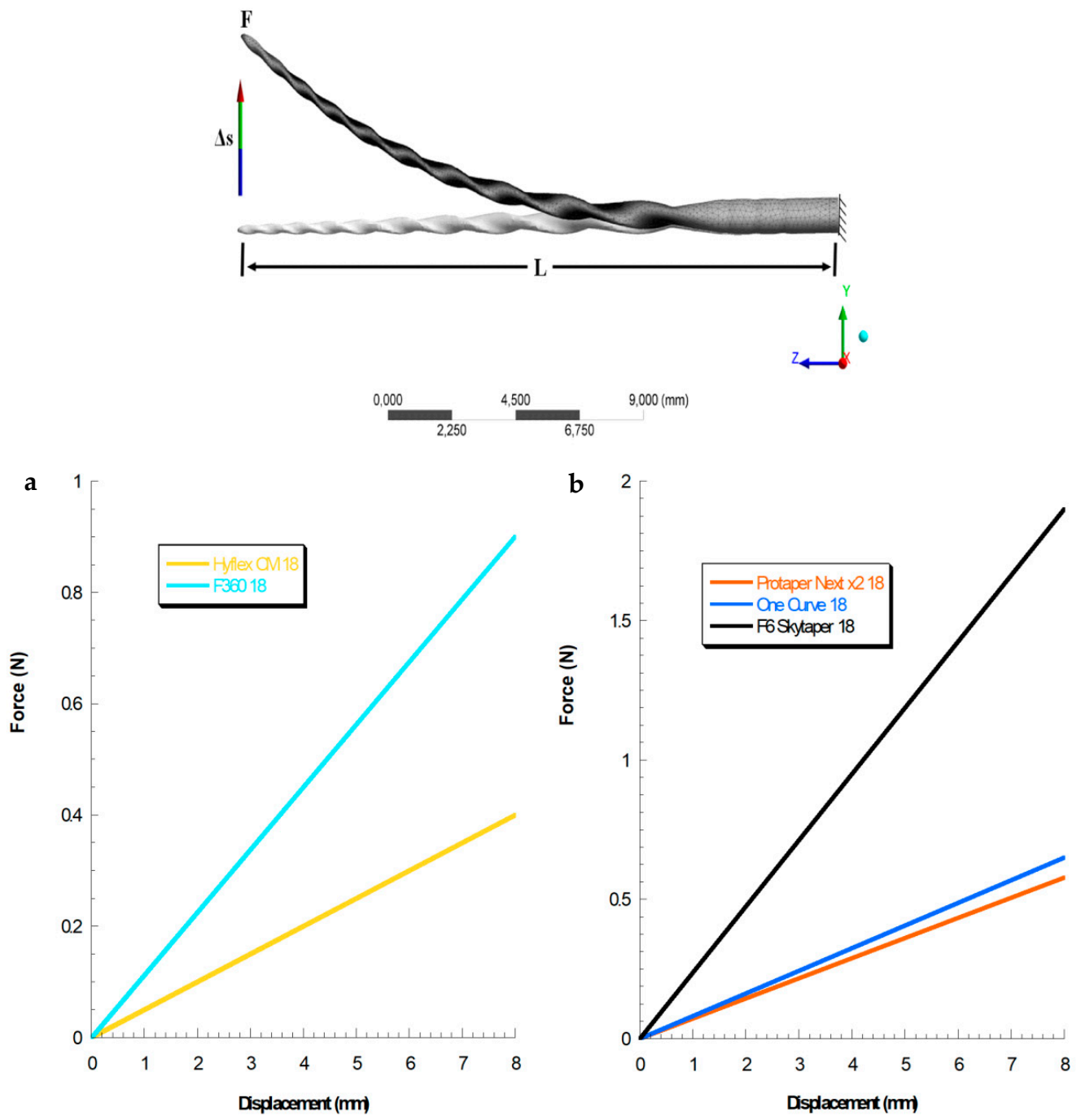

Figure 2. Reaction force in bending condition (flexibility) calculated for each instrument during the insertion into the canal. (a) Instruments with $4 \%$ conicity. (b) Instruments with $6 \%$ conicity.

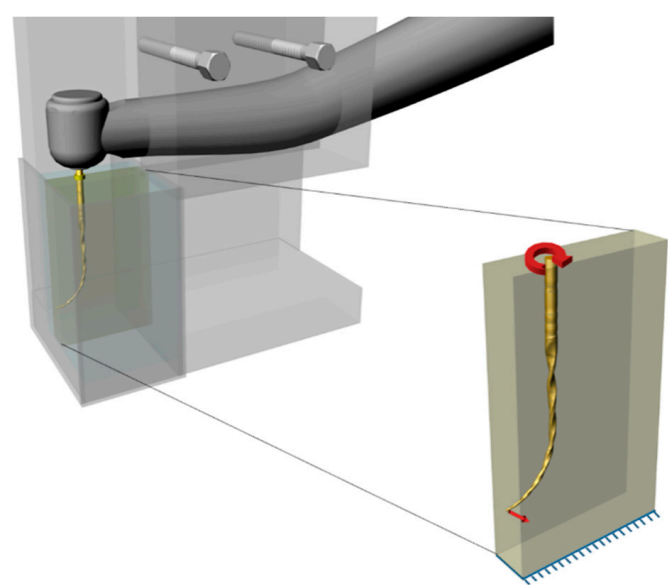

Figure 3. 3D model simulating the in vitro curved canal used for laboratorial studies. Two different loading conditions were considered at the same time: the reaction force (bending) during the instrument insertion (small red arrow) and the torque (large red arrow). Individual canals were modeled according to the instruments conicity and shape, in order to standardize the interaction with the canal walls. 
The cutting-edge motion was simulated in one direction. Therefore, during the loading phase, the instrument rotated, and its curved region pushed the dentine walls in reaction to the curved shape of the canal. For this time point, quasi-static analyses were performed with a non-failure condition since a linear elastic behavior was assumed for all components.

The results were reported in terms of strain and von Mises stress for the instruments and von Mises stress for the endodontic canals. For the endodontic instrument, a patch longitudinally to the instrument length was used to analyze and to plot the stress distribution. The stress peaks are summarized in Table 2.

\section{Results}

Each endodontic instrument was characterized by individual compliance related to the elastic modulus, maximum recommended torque, reaction force and geometry.

The curved region was the most strained in all the tested instruments. F360 Komet and F6 Skytaper, (conventional NiTi alloy), showed higher strain values compared to the other devices (Figure 4).

\section{Strain in the instrument}

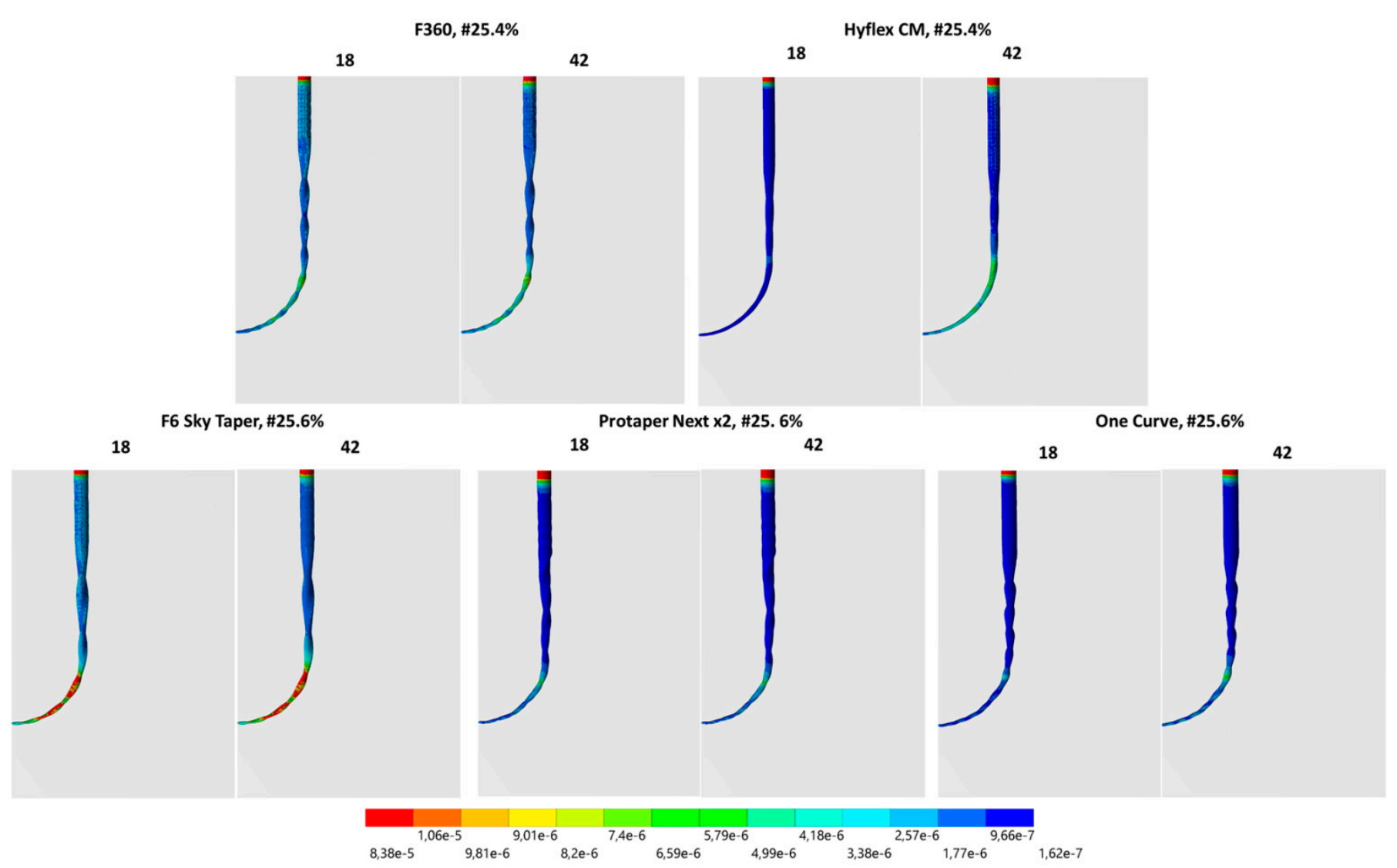

Figure 4. Strain distribution for each instrument according to the values of the elastic modulus of canal dentine (18 or $42 \mathrm{GPa})$.

In the present simulation, the elastic modulus of the dentine canal influenced the instrument strain. Specifically, higher elastic moduli ( $E=42 \mathrm{GPa}$ for highly mineralized dentine) induced higher strain gradients in all the instruments (Figure 4). A similar situation was observed for the von Mises stress distribution.

The von Mises stress distribution for each instrument is reported in Figure 5. The conventional NiTi alloy (F360 and F6 Sky Taper) showed markedly higher von Mises stress values along all the instrument section, while the heat-treated NiTi alloys (Hyflex CM, Protaper Next X2 and One Curve) showed higher values only at the curved region. In all 
cases, the most stressed region of instruments was the curved one, regardless the elastic modulus of the canal dentine and instrument conicity and design (Figure 5).

\section{Stress in the instrument}

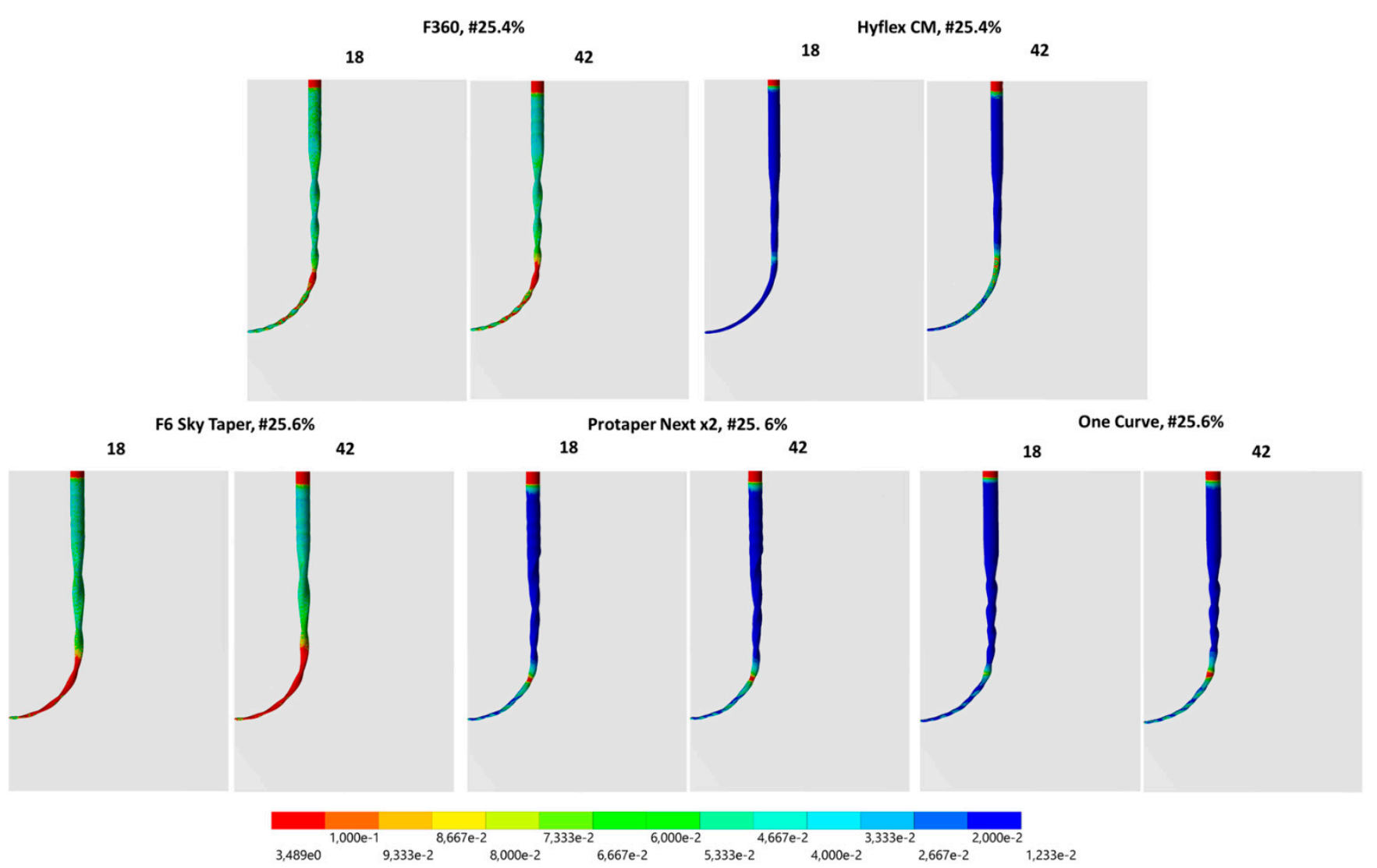

Figure 5. Von Mises stress distribution for each instrument according to the elastic modulus of the root canal (18 or $42 \mathrm{GPa})$.

The von mises stress peaks and distributions in the cross-sections of each instrument are reported in Figure 6. F6 Sky and F360 taper instruments, made of conventional alloys, showed the highest values with a similar trend in both root dentine canal models. Differently, heat treated instruments, Protaper X2, One Curve and Hyflex CM showed minor values. In particular, this last instrument revealed the lowest values, both outside and inside the instrument cross section. In both of the dentine simulated canals, Hyflex CM showed a stress peak (MPa) five or six times smaller than that of the instruments made of conventional alloys (F360 and F6, respectively). In these two cases, the external edge of the instrument cross sections underwent higher stress (red areas) and could be responsible for the initial fracture line (trigger zone) and instrument separation. 


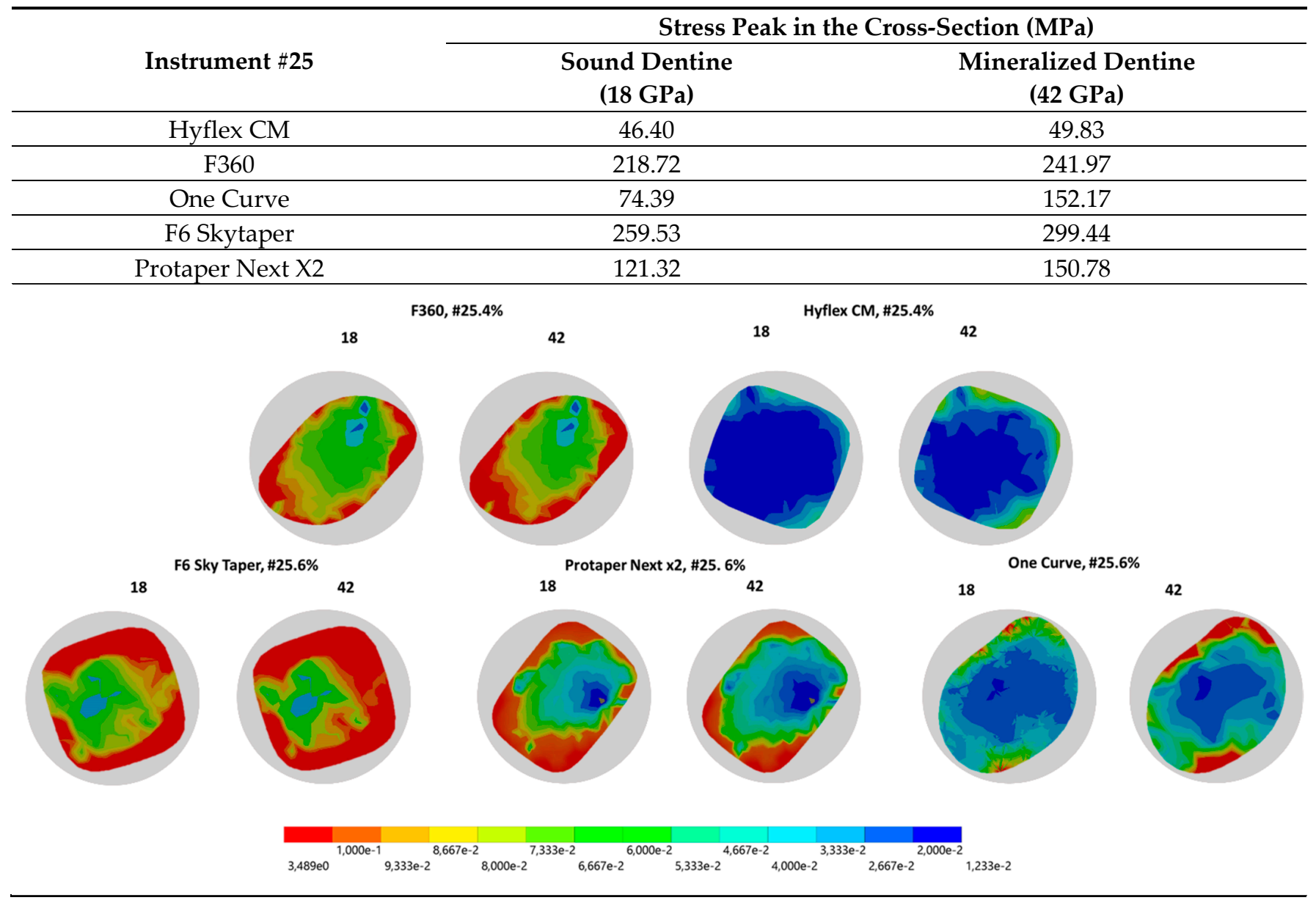

Figure 6. The highest von Mises stress peaks in the cross section (MPa) for each instrument according to the elastic modulus of the root dentine canal (18 or $42 \mathrm{GPa}$ ) are depicted. The external surface of the instrument resulted with higher stress (red area), the internal area relatively free from stress (blue color): numerically different values area reported. Interestingly, Hyflex CM was free from high stress area both in surface and in deeper area of instrument section.

The stress distribution along the instrument length can be observed in Figure 7 . In the graphs, the $y$-axis reports the stress magnitude $(\mathrm{MPa})$ and the $x$-axis represents the instrument length (from the base to the apex). As illustrated in Figure 7, the higher stress gradients can be ascribed to the values achieved in the curved region and concentrated in the first 1-2 mm of curvature radius. The stress was lower but still present at the apex of the instrument. Interestingly, Hyflex CM (conicity 4\%) showed the lowest von Mises stress values at the first curvature radius (the stress peaks were 35.73 and $44.30 \mathrm{MPa}$ for sound and mineralized dentine). F360 and F6 Skytaper (in both types of dentine) showed heterogeneous stress distributions with different peaks along the curved part of the instrument, suggesting a high level of deformation after the initial contact with the canal surface and the first stress condition (Figure 7). 


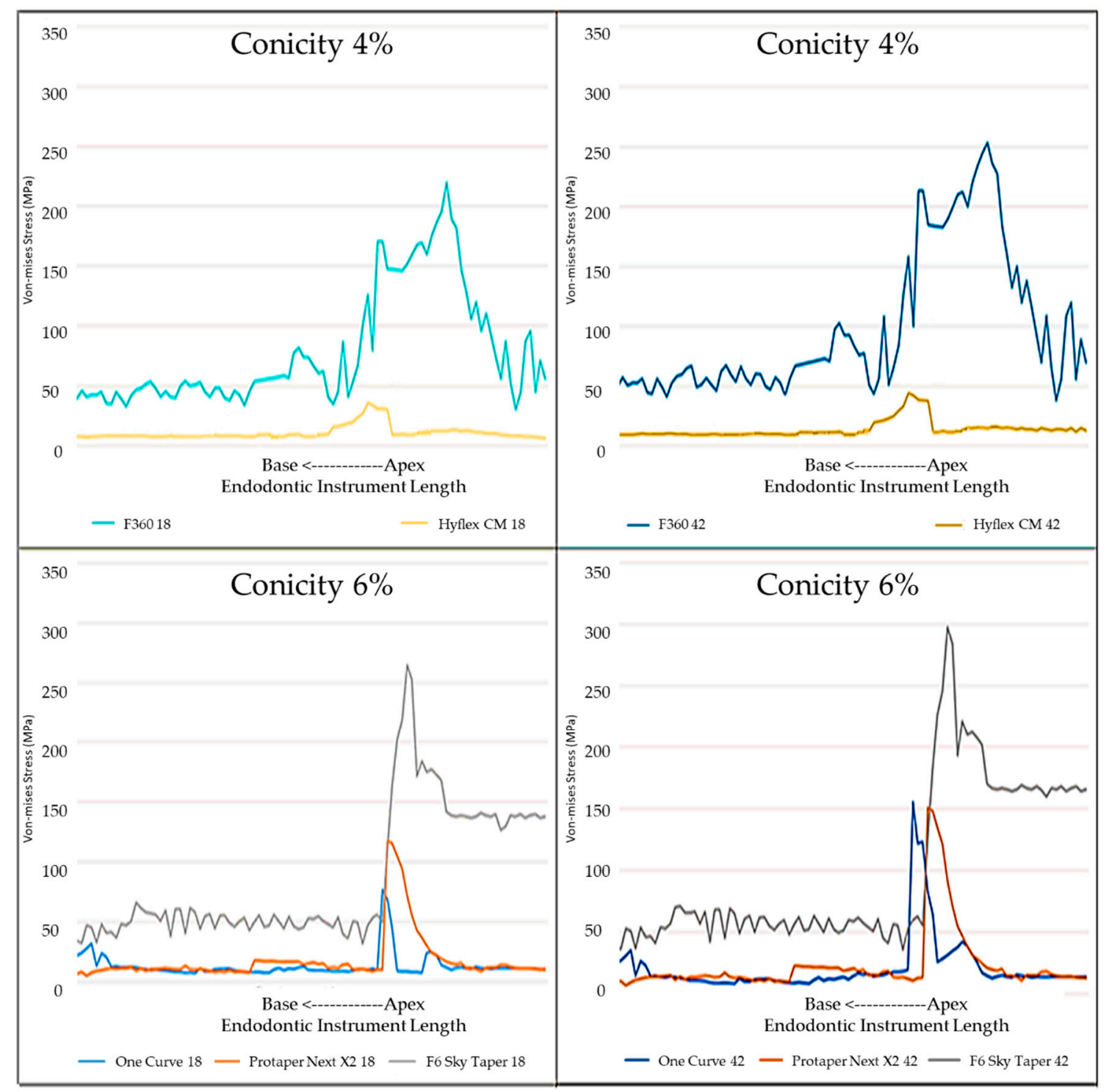

Figure 7. Von Mises stress distribution along the endodontic instrument length, from the base to the apex, according to the elastic modulus of the canal dentine (18 GPa-left or $42 \mathrm{GPa}-$ right).

The same instrument used in canals with different dentine elastic moduli (18 or $42 \mathrm{GPa})$ provided different stress distribution patterns. Higher stress levels were evident when the instrument was in contact with the most rigid mineralized dentine canal ( $\mathrm{E}=42 \mathrm{GPa})$ (i.e., the different colors along the length of the instrument in Figure 7). The lowest stress values were achieved using the Hyflex CM \#25.4\% (Figure 7).

Figure 8 shows the von Mises stress maps for the endodontic canal when a sagittal cut was performed exactly at the center of the canal. Such analysis allowed for the visualization of residual stresses generated during the simulation of the instrument movement (rotation).

The use of the conventional NiTi alloy led to a higher stress concentration and propagation in the dentine. The sound dentine (18 GPa) seemed to be slightly more stressed than the highly mineralized dentine ( $42 \mathrm{GPa})$, especially at the most coronal portion of the dentine canal. 


\section{Stress in the canal}

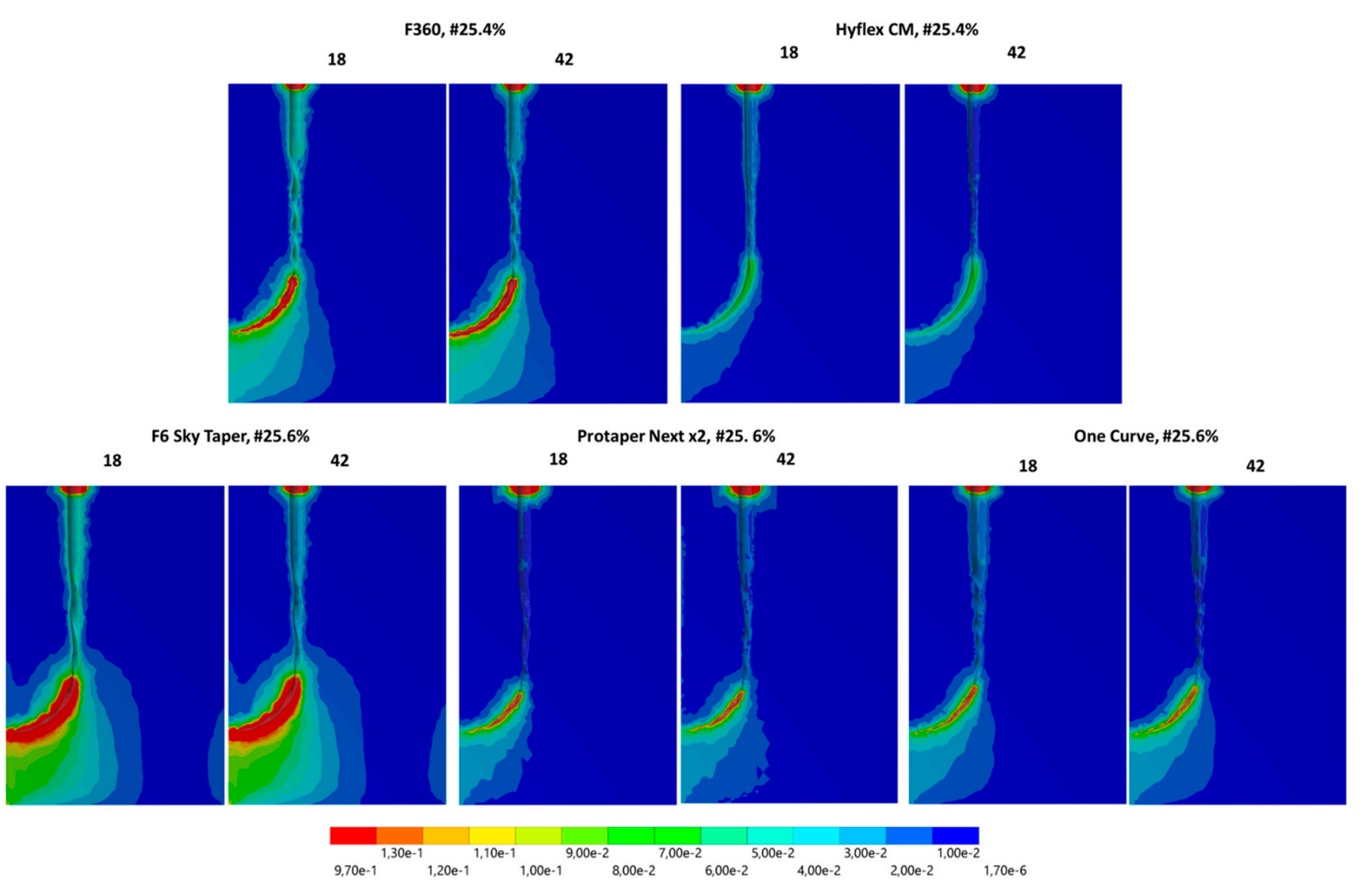

Figure 8. Von Mises stress distribution and propagation in the dentine with the two different values of dentine elastic modulus (18 or $42 \mathrm{GPa})$.

\section{Discussion}

The present investigation analyzed the influence of conventional or heat-treated $\mathrm{NiTi}$ alloys of five commercially available NiTi endodontic instruments. Stress and strain distributions during rotation in two selected dentine canal models, simulating a sound dentine (18 GPa) or a highly mineralized dentine canal (42 GPa), were considered. The root canal model used in this study was characterized by a specific design with a curve approximately at the medium-apical third, as used in different studies for fatigue test evaluation [22-28], granting the opportunity to compare the results and information.

In the present study, instruments with a conicity of $4 \%$ were tested in a canal model with the same conicity, while instruments with $6 \%$ conicity were tested in the canal model of $6 \%$ in order to simulate similar conditions and to provide a comparable friction surface. This was an innovative approach, addressing a drawback of previous mechanical studies in which all instruments were tested in the same metallic canal model.

Another innovative approach is represented by the volume measurement of the instruments. The volume is in relationship with the design, conicity and geometrical features. The instrument with a higher volume may "fill" the root canal space and increase stress and friction along the dentine canal.

Specifically, using this canal model, the FEA demonstrated a well-defined peak of stress in the same location in the correspondence of canal curvature for all instruments (approximately at $7 \mathrm{~mm}$ from the apex/tip of the instrument). This peak was extremely abrupt for conventional alloys with very high von Mises stress level distributions (see 
Figure 7) and, in particular, in the most rigid and curved dentine canal models. The null hypothesis was consequently rejected.

Endodontic rotary instruments are normally subjected, in a curved canal, to both compressive and tensile stresses: the concave portion of the instrument is under compression while the external portion is under tension [38]. In this study, all the heat-treated alloy instruments showed distinctly lower von Mises stress and strain values in both straight and curved regions of the different dentine root canals than the conventional ones. These data were also confirmed by the analyses on the endodontic cross sections, as reported in Figure 6, where in a section plane, the highest von Mises stress magnitudes for each instrument according to the elastic modulus of the root canal model (18 or $42 \mathrm{GPa}$ ) was summarized. Regarding the different instruments Hyflex CM and One Curve showed the best mechanical rotating behaviors. Recent in vitro investigations [39] confirmed, from a mechanical viewpoint, the influence of different heat treatments on the torsional and cyclic fatigue resistance of rotary instruments.

The cross section was reported as being one of the most important variables in von Mises stress distributions for conventional alloy instruments [1,31]. F360 and F6 Skytaper are both conventional based NiTi alloys (Table 1). In particular, F360 has an S-shaped crosssection, while F6 skytaper has a quadrangular cross section. These instruments exhibited the highest stress magnitude (298.01 and 253.41 MPa respectively) in high mineralized dentine canals, irrespective of their cross section.

Heat treatment allows for a higher presence of martensitic and $\mathrm{R}$ phases in NiTi instruments at room and body temperature, lowering their elastic moduli, improving the instrument flexibility and, as consequence, also improving the von Mises stress and strain patterns in simulated clinical conditions $[9,10]$.

Other investigated instruments include those based on heat-treated NiTi alloys. One Curve was characterized by a variable asymmetrical cross-section, which becomes S-shaped near the top of the shaft and then more triangular at the tip.

ProTaper Next X2 has an off-centered rectangular cross-section. Despite this difference in cross-section, both Protaper Next X2 and One curve instruments showed similar stress peak values (155.50 and $151.02 \mathrm{MPa}$, respectively).

Interestingly, Hyflex CM showed markedly lower stress peak values (35.73 and $44.30 \mathrm{MPa})$ in both types of dentine (18 and $42 \mathrm{GPa}$, respectively) and demonstrated a low stress distribution along the curved dentine canal. Hyflex $\mathrm{CM}$ alloys are characterized by a quadrangular cross section with four blades and four flutes. They are obtained through an thermomechanical process in which the NiTi alloy shows "controlled memory" properties rather than "superelastic properties" [23]. Their diameter and conicity (\#25 0.4) are associated with a reduced volume and higher flexibility in bending. Therefore, an elastic instrument-such as Hyflex $\mathrm{CM}$ - may rotate (and work) for a greater time inside the root canal with a reduced risk of fracture.

From a clinical point of view, it is important to prevent any unexpected instrument separation/fracture inside the root canal. NiTi instruments may rotate inside the root dentine canal for approximately $30 \mathrm{~s}$ [38], but a complex canal anatomy may require more time. It has been documented that 40-120 s may represent a sufficient time to fracture $[23,25]$. The operator should be able to evaluate the portion of the canal in which the stress is higher in order to prevent any risk of instrument fracture. Endodontic instruments produce-during their rotational movement-a great amount of debris mainly composed of predentine and dentine, a smear layer, and collagen-pulpal debris which must be removed from the root canal lumen $[40,41]$. Their effect on friction must be evaluated in future studies.

Many studies have reported rapid surface deterioration of NiTi instruments, as detected by scanning electron microscopy (SEM), environmental scanning electron microscopy (ESEM) coupled with energy-dispersive X-ray analysis (EDX) and by metallurgical analysis [22,23]. The presence of small alloy defects and small cracks induce a fast fracture formation, easily detectable via SEM fractographic inspection [22,23]. 
The elastic modulus of the dentine canal affects the stress and strain distributions of rotary instruments. The different mineralization of different types of dentine (sound and highly mineralized root dentine) represents a critical factor and greatly contributes to the fracture risk for instruments in the area (radius of root canal) where stress is concentrated [22-24]. In particular, the higher the elastic modulus, the more rigid the dentine and the higher the strain and stress concentrations for the instrument. Interestingly, as shown by the von Mises stress distribution, the higher concentration of the stress was located at the initial part of the curvature of the root canal (and of the instrument), approximately $7 \mathrm{~mm}$ from the apex/tip of the instrument.

The frictional contact, assumed as being 0.2 between all instruments and root canal models, is a simplification that does not occur clinically. This value was considered in the present simulation to standardize the processing step and allow for comparison between the results. Further in vitro tests must be carried out to calculate the optimal coefficient that should be used for each instrument and dentin tissue.

The FEA demonstrated that the stress induced by rotating instruments in the dentine canal created a stress propagation into a large area of deep dentine and was easily detectable at 3-4 $\mathrm{mm}$ from the canal wall. This means that all apical root dentin thicknesses are stressed by instrument movement (rotation). The stress propagation was evident along the entire radius of the root curvature, from the coronal to the apex direction as a sort of "stress tunnel". It does not represent a peak, but a well-defined area with different stress gradients. Similar to other mineralized human tissues, the root dentin presents a quasi-brittle characteristic and anisotropy of the mechanical properties under shear stress.

In the present study a standard root canal configuration model with a "smooth dentine surface" was used, as previously suggested in recent mechanical studies [27,28]. Future investigations must be carried out to evaluate the influence of irregular surfaces on the 3D canal configuration (for example, the presence of predentine) and different levels of dentine hardness (elastic modulus), which may create a cliff in the length of canal during the "navigation" from the coronal area to the apex of the root.

\section{Conclusions}

Within the limits of the present investigation, this study demonstrates that:

1. cross-sectional design, volume and elasticity, in addition to the elastic modulus of the root canal dentine influence the mechanical response of the instruments;

2. the curved region of the instruments was proven to exhibit the highest stress concentration;

3. stress propagation-induced by instruments - affects a large dentin area, from the curvature region to the apical root;

4. The heat-treated NiTi alloy displayed lower stress values and lower strain concentration levels in the root canal dentine when compared to the conventional NiTi.

Clinical operators must know the mechanical properties of new and conventional NiTi instruments based on different alloys and select them on the basis of their design and properties.

Author Contributions: Conceptualization, P.A., J.P.M.T., A.M.d.O.D.P., A.L.S.B., M.V., C.P.; methodology, P.A., J.P.M.T., A.L.S.B., M.V., C.P.; software, P.A., J.P.M.T., A.L.S.B.; validation, P.A., J.P.M.T., A.M.d.O.D.P., A.L.S.B., M.V., F.Z., C.P.; formal analysis, P.A., J.P.M.T., A.M.d.O.D.P., A.L.S.B., M.V., C.P.; investigation, P.A., J.P.M.T., A.M.d.O.D.P., A.L.S.B., M.V., C.P.; resources, P.A., J.P.M.T., C.P.; data curation, P.A., J.P.M.T., A.M.d.O.D.P., A.L.S.B., M.V., F.Z., C.P.; writing-original draft preparation, P.A., J.P.M.T., A.M.d.O.D.P., A.L.S.B., M.V., F.Z., C.P.; writing-review and editing, P.A., J.P.M.T., A.M.d.O.D.P., A.L.S.B., M.V., F.Z., C.P.; visualization, P.A., J.P.M.T., A.M.d.O.D.P., A.L.S.B., M.V., F.Z., C.P.; supervision, P.A. and C.P.; project administration, P.A., J.P.M.T., A.M.d.O.D.P., C.P.; funding acquisition, P.A. All authors have read and agreed to the published version of the manuscript.

Funding: This research received no external funding.

Institutional Review Board Statement: Not applicable. 
Informed Consent Statement: Not applicable.

Data Availability Statement: The data presented in this study are available on request from the corresponding author.

Conflicts of Interest: The authors declare no conflict of interest. The funders had no role in the design of the study; in the collection, analyses, or interpretation of data; in the writing of the manuscript, or in the decision to publish the results.

\section{References}

1. de Arruda Santos, L.; López, J.B.; de Las Casas, E.B.; de Azevedo Bahia, M.G.; Buono, V.T. Mechanical behavior of three nickel-titanium rotary files: A comparison of numerical simulation with bending and torsion tests. Mater. Sci. Eng. C Mater. Biol. Appl. 2014, 37, 258-263. [CrossRef]

2. Iqbal, M.K.; Kohli, M.R.; Kim, J.S. A retrospective clinical study of incidence of root canal instrument separation in an endodontics graduate program: A PennEndo database study. J. Endod. 2006, 32, 1048-1052. [CrossRef] [PubMed]

3. Parashos, P.; Messer, H.H. Rotary NiTi instrument fracture and its consequences. J. Endod. 2006, 32, 1031-1043. [CrossRef] [PubMed]

4. Zhao, Y.; Li, J.; Guo, K.; Sivalingam, V.; Sun, J. Study on chip formation characteristics in turning NiTi shape memory alloys. J. Manuf. Process. 2020, 58, 787-795. [CrossRef]

5. Gil, J.; Rupérez, E.; Velasco, E.; Aparicio, C.; Manero, J.M. Mechanism of fracture of NiTi superelastic endodontic rotary instruments. J. Mater. Sci. Mater. Med. 2018, 29, 131. [CrossRef]

6. Palma, P.J.; Messias, A.; Cerqueira, A.R.; Tavares, L.D.; Caramelo, F.; Roseiro, L.; Santos, J.M. Cyclic fatigue resistance of three rotary file systems in a dynamic model after immersion in sodium hypochlorite. Odontology 2019, 107, 324-332. [CrossRef]

7. Lo Giudice, R.; Lizio, A.; Cervino, G.; Fabiana, N.; Francesco, P.; Ausiello, P.; Cicciù, M. The Horizontal Root Fractures. Diagnosis, Clinical Management and Three-Year Follow-Up. Open Dent. J. 2018, 28, 687-695. [CrossRef]

8. Miyai, K.; Ebihara, A.; Hayashi, Y.; Doi, H.; Suda, H.; Yoneyama, T. Influence of phase transformation on the torsional and bending properties of nickel-titanium rotary endodontic instruments. Int. Endod. J. 2006, 39, 119-126. [CrossRef]

9. Berutti, E.; Chiandussi, G.; Gaviglio, I.; Ibba, A. Comparative analysis of torsional and bending stresses in two mathematical models of nickel-titanium rotary instruments: ProTaper versus ProFile. J. Endod. 2003, 29, 15-19. [CrossRef]

10. Zupanc, J.; Vahdat-Pajouh, N.; Schäfer, E. New thermomechanically treated NiTi alloys-A review. Int. Endod. J. 2018, 51, 1088-1103. [CrossRef]

11. Tabassum, S.; Zafar, K.; Umer, F. Nickel-Titanium Rotary File Systems: What's New? Eur. Endod. J. 2019, 18, 111-117.

12. Melo, M.C.; Pereira, E.S.; Viana, A.C.; Fonseca, A.M.; Buono, V.T.; Bahia, M.G. Dimensional characterization and mechanical behaviour of K3 rotary instruments. Int. Endod. J. 2008, 41, 329-338. [CrossRef]

13. Kim, T.O.; Cheung, G.S.; Lee, J.M.; Kim, B.M.; Hur, B.; Kim, H.C. Stress distribution of three NiTi rotary files under bending and torsional conditions using a mathematic analysis. Int. Endod. J. 2009, 42, 14-21. [CrossRef] [PubMed]

14. Zhang, R.; Hu, T. Root canal curvature. Int. Endod. J. 2010, 436, 16-18. [CrossRef] [PubMed]

15. Martorelli, M.; Ausiello, P. A novel approach for a complete 3D tooth reconstruction using only 3D crown data. Int. J. Interact. Des. Manuf. 2013, 7, 125-135. [CrossRef]

16. Ausiello, P.; Ciaramella, S.; Garcia-Godoy, F.; Martorelli, M.; Sorrentino, R.; Gloria, A. Stress distribution of bulk-fill resin composite in class II restorations. Am. J. Dent. 2017, 30, 227-232.

17. Tribst, J.P.M.; Dal Piva, A.M.O.; Lo Giudice, R.; Borges, A.L.S.; Bottino, M.A.; Epifania, E.; Ausiello, P. The Influence of CustomMilled Framework Design for an Implant-Supported Full-Arch Fixed Dental Prosthesis: 3D-FEA Study. Int. J. Environ. Res. Public Health 2020, 17, 4040. [CrossRef] [PubMed]

18. Gloria, A.; Maietta, S.; Martorelli, M.; Lanzotti, A.; Watts, D.C.; Ausiello, P. FE analysis of conceptual hybrid composite endodontic post designs in anterior teeth. Dent. Mater. 2018, 34, 1063-1071. [CrossRef] [PubMed]

19. Ausiello, P.; Ciaramella, S.; Di Rienzo, A.; Lanzotti, A.; Ventre, M.; Watts, D.C. Adhesive class I restorations in sound molar teeth incorporating combined resin-composite and glass ionomer materials: CAD-FE modeling and analysis. Dent. Mater. 2019, 35, 1514-1522. [CrossRef]

20. Penteado, M.M.; Tribst, J.P.M.; Dal Piva, A.M.; Ausiello, P.; Zarone, F.; Garcia-Godoy, F.; Borges, A.L. Mechanical behavior of conceptual posterior dental crowns with functional elasticity gradient. Am. J. Dent. 2019, 32, 165-168.

21. Versluis, A.; Kim, H.C.; Lee, W.; Kim, B.M.; Lee, C.J. Flexural stiffness and stresses in nickel-titanium rotary files for various pitch and cross-sectional geometries. J. Endod. 2012, 38, 1399-1403. [CrossRef]

22. Pirani, C.; Cirulli, P.P.; Chersoni, S.; Micele, L.; Ruggeri, O.; Prati, C. Cyclic fatigue testing and metallographic analysis of nickel-titanium rotary instruments. J. Endod. 2011, 37, 1013-1016. [CrossRef]

23. Pirani, C.; Iacono, F.; Generali, L.; Sassatelli, P.; Nucci, C.; Lusvarghi, L.; Gandolfi, M.G.; Prati, C. HyFlex EDM: Superficial features, metallurgical analysis and fatigue resistance of innovative electro discharge machined NiTi rotary instruments. Int. Endod. J. 2016, 49, 483-493. [CrossRef]

24. Pedullà, E.; Lo Savio, F.; Boninelli, S.; Plotino, G.; Grande, N.M.; La Rosa, G.; Rapisarda, E. Torsional and Cyclic Fatigue Resistance of a New Nickel-Titanium Instrument Manufactured by Electrical Discharge Machining. J. Endod. 2016, 42, 156-159. [CrossRef] 
25. Gambarini, G.; Grande, N.M.; Plotino, G.; Somma, F.; Garala, M.; De Luca, M.; Testarelli, L. Fatigue resistance of engine-driven rotary nickel-titanium instruments produced by new manufacturing methods. J. Endod. 2008, 34, 1003-1005. [CrossRef]

26. Plotino, G.; Grande, N.M.; Melo, M.C.; Bahia, M.G.; Testarelli, L.; Gambarini, G. Cyclic fatigue of NiTi rotary instruments in a simulated apical abrupt curvature. Int. Endod. J. 2010, 43, 226-230. [CrossRef] [PubMed]

27. Iacono, F.; Pirani, C.; Arias, A.; de la Macorra, J.C.; Generali, L.; Gandolfi, M.G.; Prati, C. Impact of a modified motion on the fatigue life of NiTi reciprocating instruments: A Weibull analysis. Clin. Oral Investig. 2019, 23, 3095-3102. [CrossRef]

28. Iacono, F.; Pirani, C.; Generali, L.; Bolelli, G.; Sassatelli, P.; Lusvarghi, L.; Gandolfi, M.G.; Giorgini, L.; Prati, C. Structural analysis of HyFlex EDM instruments. Int. Endod. J. 2017, 50, 303-313. [CrossRef]

29. Plotino, G.; Grande, N.M.; Cordaro, M.; Testarelli, L.; Gambarini, G. A Review of Cyclic Fatigue Testing of Nickel-Titanium Rotary Instruments. J. Endod. 2009, 35, 1469-1476. [CrossRef] [PubMed]

30. Zhang, E.W.; Cheung, G.S.; Zheng, Y.F. Influence of cross-sectional design and dimension on mechanical behavior of nickeltitanium instruments under torsion and bending: A numerical analysis. J. Endod. 2010, 36, 1394-1398. [CrossRef] [PubMed]

31. De Arruda Santos, L.; De Azevedo Bahia, M.G.; De Las Casas, E.B.; Buono, V.T.L. Comparison of the mechanical behavior between controlled memory and superelastic nickel-titanium files via finite element analysis. J. Endod. 2013, 39, 1444-1447. [CrossRef] [PubMed]

32. Lee, M.H.; Versluis, A.; Kim, B.M.; Lee, C.J.; Hur, B.; Kim, H.C. Correlation between experimental cyclic fatigue resistance and numerical stress analysis for nickel-titanium rotary files. J. Endod. 2011, 37, 1152-1157. [CrossRef]

33. Scattina, A.; Alovisi, M.; Paolino, D.S.; Pasqualini, D.; Scotti, N.; Chiandussi, G.; Berutti, E. Prediction of Cyclic Fatigue Life of Nickel-Titanium Rotary Files by Virtual Modeling and Finite Elements Analysis. J. Endod. 2015, 41, 1867-1870. [CrossRef] [PubMed]

34. Bonessio, N.; Arias, A.; Lomiento, G.; Peters, O.A. Effect of root canal treatment procedures with a novel rotary nickel titanium instrument (TRUShape) on stress in mandibular molars: A comparative finite element analysis. Odontology 2017, 105, 54-61. [CrossRef]

35. De Andrade, G.S.; Tribst, J.P.M.; Orozco, E.I.; Augusto, M.G.; Bottino, M.A.; Borges, A.L.; Anami, L.C.; Saavedra, G.D. Influence of different post-endodontic restorations on the fatigue survival and biomechanical behavior of central incisors. Am. J. Dent. 2020, 33, 227-234.

36. Zhang, Y.R.; Du, W.; Zhou, X.D.; Yu, H.Y. Review of research on the mechanical properties of the human tooth. Int. J. Oral Sci. 2014, 6, 61-69. [CrossRef] [PubMed]

37. Pereira, E.S.; Gomes, R.O.; Leroy, A.M.; Singh, R.; Peters, O.A.; Bahia, M.G.; Buono, V.T. Mechanical behavior of M-Wire and conventional NiTi wire used to manufacture rotary endodontic instruments. Dent. Mater. 2013, 29, 318-324. [CrossRef] [PubMed]

38. Cheung, G.S. Instrument fracture: Mechanisms, removal of fragments, and clinical outcomes. Endod. Top. 2009, 16, 1-26. [CrossRef]

39. Gambarini, G.; Cicconetti, A.; Nardo, D.D.; Miccoli, G.; Zanza, A.; Testarelli, L.; Serracchiani, M. Influence of different heat treatments on torsional and cyclic fatigue resistance of nickel-titanium rotary files: A comparative study. Appl. Sci. 2020, 10, 5604. [CrossRef]

40. Foschi, F.; Nucci, C.; Montebugnoli, L.; Marchionni, S.; Breschi, L.; Malagnino, V.A.; Prati, C. SEM evaluation of canal wall dentine following use of Mtwo and ProTaper NiTi rotary instruments. Int. Endod. J. 2004, 37, 832-839. [CrossRef]

41. Prati, C.; Foschi, F.; Nucci, C.; Montebugnoli, L.; Marchionni, S. Appearance of the root canal walls after preparation with NiTi rotary instruments: A comparative SEM investigation. Clin. Oral Investig. 2004, 8, 102-110. [CrossRef] [PubMed] 